\title{
Simulation of Creative Manifestation by Functional Ensembles of Intellectual Agents Based on Live Information in Various Spheres of Life Activity
}

\author{
Evgeny Bryndin ${ }^{1}$ \\ ${ }^{1}$ Research Department, Research Center "NATURAL INFORMATICS”, Novosibirsk, Russia \\ Correspondence: Evgeny Bryndin, Research Department, Research Center "NATURAL INFORMATICS", \\ Novosibirsk, Russia. E-mail: bryndin15@yandex.ru
}

Received: December 23, 2021 Accepted: December 31, 2021 Online Published: December 31, 2021

doi:10.5539/nct.v6n2p41

URL: https://doi.org/10.5539/nct.v6n2p41

\begin{abstract}
Neural networks with deep learning and reinforcement are able to compose poetry and music, draw paintings, and write short stories, as well as come up with scripts for films. Functional ensembles of harmoniously interacting intellectual agents with living information can virtually model creativity for various spheres of life activity. Virtual modeling of creativity by harmoniously interacting intellectual agents is carried out based on living creative processes represented by acts of creation accumulated by humanity in a certain sphere of life. Live information of creative acts of creation for functional ensembles from harmoniously interacting intellectual agents is revealed from the effective creative practice of specialists in specific conditions and presented in the format of smart ethical communicative-associative cases. To model creativity, a virtual environment of a certain sphere of activity is formed, in which the ensemble gives birth to a creative fruit according to the plan of a specialist. Functional ensembles of harmoniously interacting intellectual agents with live creative practice can cooperate with a person, and can also independently virtually model the creative creation of new designs of a specialist, if the ensemble has enough acts of creation.
\end{abstract}

Keywords: creative modeling, intelligent agents, live information, virtual environment.

\section{Introduction}

With the development of neural networks, they come up with more and more diverse methods of application. They teach Tesla autopilots, and facial recognition is used not only for processing photos by applications like Prisma, but also in security systems. Artificial intelligence is taught to diagnose diseases. In the end, with his help, elections win.

But there is one sphere that has traditionally been considered to belong exclusively to man - creativity. However, this statement is beginning to be called into question. Lee Cedol, who lost the AlphaGo, admitted: "The defeat made me doubt human creativity. When I saw how AlphaGo plays, I doubted how well I play myself." Is artificial intelligence capable of stepping into the territory of creativity, into the space of perception.

Nature is a sweet, familiar and beloved creature on the heart. Nature is one of the most important sources from which creative people draw inspiration. Nature is a muse for people's creativity.

In the history of our country there are many famous people whose work was strongly influenced by nature. One of them is Alexander Sergeevich Pushkin. "Boldinsky Autumn" is the brightest period in his work. While in the village of Boldino, the writer revealed himself in many genres and wrote a large number of works. What attracted Pushkin this village? And the fact is that he in Boldino found a muse that did not leave him either for days or nights. This muse is nature.

Yasnaya Polyana had a great influence on the work of the writer Lev Nikolaevich Tolstoy. It was here, in his native estate, that Lev Nikolaevich felt like an artist. It was here that he was first visited by inspiration, which later glorified the writer as an exponent of Russian nature. It was here that images were born, which later entered many of the writer's works.

Nature and creative people are closely interconnected. Nature is the main source of inspiration for them. 
A person has the ability to see the beautiful. Here, a man saw the depth of the blue sky, the flickering in the dark night of beautiful and mysterious stars, crimson sunset before a windy day, a gentle pink dawn nascent day, the wild beauty of the steppes, a crane pack in celestial azure, the reflection of the sun in clear droplets of morning dew, gray threads of rain in overcast autumn, a gentle stalk and blue - saw and was amazed and began to create his beauty, in his heart.

A man became creative when he heard a whisper of autumn leaves and fell in love with him, heard a bird's song and tried to convey it through sound reproduction and the creation of many musical instruments. When he managed to convey through his works of art the magazine of the spring stream and the ringing of the silver bells of the lark in the bottomless sky, he noticed the uniqueness of each snowflake and the longing from the curling of the snow blizzard outside the window, the affectionate shoulder of the wave and the solemn silence of the night. Man heard all this and, holding his breath, listens to the wonderful music and poetry of nature for hundreds and thousands of years. The world around us is reflected in a person's emotional state. Nature always inspires man, gives him a sense of beauty and harmony with the world.

Left alone with nature, a person can understand himself and find answers to all the questions of interest. This is her creative influence. Good nature has taken care of everything so that everywhere you find something to learn (Leonardo da Vinci). Man is endowed by the Creator with power over external nature, while in his work he is subordinate to it (Georg Hegel). Nature is a pleasant mentor, and not so much pleasant as careful and faithful (Michel Montaigne).

Humans are part of nature. At every step you can notice the influence of nature on human creativity. People tried to comprehend various elements and describe the impact of external forces on their activities. The consequence of this influence is the fact that the interaction of human activity and nature very often gives impetus to various creations. Nature fills the heart with the beauty of forests and flowering meadows, bright positive emotions, awakens joyful feelings, sows good and pushes for new creations. Usually, after a long stay in nature, the mind seems to be purifying, it begins to be filled with new thoughts and ideas that immediately want to run and implement. Simply put, we are inspired.

Everything that happens to people since their appearance is connected with spiritual laws, especially harmony, creativity and beauty. The ideal is the life of people in harmony with nature. Nature is perfect in terms of harmony and beauty.

Nature has creative qualities. It reproduces flowers, trees, grass, etc., in certain conditions, with living information about them. By feeding on the wildlife information of objects, processes, phenomena, connections and laws, man becomes the creator of living knowledge and living practice (Bryndin, 2021a).

The living information of Nature represents the communication vibrations of its essence. Man has a natural mechanism of creative activity with wildlife information of Nature. The mental biopolis of the mind perceives the communicative vibrations of Nature. When perceived natural communicative vibrations come into resonance with the vibrations of psychic energy of the associative neural network systems of the brain, then their figurative or linguistic similarity arises depending on the concentration of attention.

The article is devoted to the formation and creative manifestation of functional ensembles of intellectual agents based on live information.

The second section is devoted to the formation of a platform for a virtual creative living environment. It examines the presentation of creative acts by intelligent ethical communicative-associative cases and professional images of intellectual agents.

The third section describes the platform of creative ensembles of intellectual agents with smart hybrid competencies and functional harmonious self-organization of large ensembles of intellectual agents according to the law of gold section (Bryndin, 2021b).

The fourth section examines aspects of modeling creative activities by ensembles of intelligent agents in a virtual environment.

\section{Building Virtual Creative Living Environment Platform}

\subsection{Presentation of Information on Creative Acts by Smart Ethical Communicative-Associative Cases}

The presentation of living information of creative acts of specialists in a virtual creative environment is carried out by smart ethical communicative-associative cases. They use both attributes and sets of entities, processes, relationships, as well as parameters, characteristics, methods, digital models of human twins, knowledge, skills, behavior, images and other objects of harmonious interaction of ensembles of intellectual agents. For example: 


\begin{tabular}{ll}
\hline 1. & Presentation of information on creative acts \\
\hline 2. Use case name & $\begin{array}{l}\text { Smart ethical communicative-associative communications of ensembles of } \\
\text { intellectual agents }\end{array}$ \\
\hline 3. Application domain & work and life \\
\hline 5. Objective(s) & hybrid \\
\hline & Harmonious and universal application of large ensembles of intellectual agents \\
\hline & $\begin{array}{l}\text { The standard case defines the properties, characteristics and attributes for } \\
\text { functionally interfacing intellectual agents with competent images of smart hybrid } \\
\text { competencies. They determine the state of stable equilibrium that arises from the } \\
\text { correct distribution, combination, interaction of intelligent agents. To obtain the } \\
\text { necessary result, competent images of intelligent agents with smart hybrid } \\
\text { competencies are formed. The functions of interaction of intellectual agents of the } \\
\text { ensemble are set. According to the law of gold cross-section, the critical value of } \\
\text { intellectual agents is determined. Then the functional self-organization of the } \\
\text { ensemble is carried out by achieving synergy in the functions of interaction of } \\
\text { intellectual agents. Then the ensemble adapts to a specific environment. As a result } \\
\text { of harmonious functional self-organization, in accordance with the standard case, a } \\
\text { target ensemble of intellectual agents is formed to obtain the necessary result. }\end{array}$ \\
\hline
\end{tabular}

7. Stakeholders and Highly technological producer and user.

stakeholder considerations Legal and ethical aspects of interaction with society

\begin{tabular}{|c|c|c|}
\hline 8. Data Characteristics & \multicolumn{2}{|c|}{$\begin{array}{l}\text { logical models, } \\
\text { real time, } \\
\text { streams of professional images, } \\
\text { smart, } \\
\text { regulated attribute, }\end{array}$} \\
\hline $\begin{array}{l}\text { 9. Key performance } \\
\text { indicators (KPIs) }\end{array}$ & \multicolumn{2}{|c|}{$\begin{array}{l}\text { AI management of professional cooperation process. } \\
\text { Improve of synergy between agents. }\end{array}$} \\
\hline \multirow{5}{*}{ 10. Features of use case } & Task(s) & $\begin{array}{l}\text { 1.Safe interaction of technocratic societies. } \\
2 \text {.Building high-tech synergies of technocratic societies. }\end{array}$ \\
\hline & Level of automation & high automation \\
\hline & Method(s) & $\begin{array}{l}\text { Ethical language, behavioural and active communication } \\
\text { and utility and preference criteria }\end{array}$ \\
\hline & Platform & $\begin{array}{l}\begin{array}{l}\text { Supercomputer with Strong Artificial Distributed } \\
\text { Intelligence. }\end{array} \\
\end{array}$ \\
\hline & Topology & Distributed Modular Interconnect Topology. \\
\hline 11. Threats \& vulnerabilities & \multicolumn{2}{|c|}{ Ethical aspects of interaction with society. } \\
\hline 12. Challenges and issues & \multicolumn{2}{|c|}{ Reputation, responsibility, security. } \\
\hline $\begin{array}{l}\text { 13. Trustworthiness } \\
\text { considerations }\end{array}$ & \multicolumn{2}{|c|}{$\begin{array}{l}\text { Security and ethical models of harmonious self-organization of large ensembles. } \\
\text { A universal approach to the ethical and safe use of intellectual agent ensembles } \\
\text { with language behavioral and active communications. Based on new data, } \\
\text { confirm that the ensemble of intelligent agents performs trained professional } \\
\text { process. }\end{array}$} \\
\hline $\begin{array}{l}\text { Use of standards; } \\
\text { standardization } \\
\text { opportunities }\end{array}$ & \multicolumn{2}{|c|}{$\begin{array}{l}\text { Creative process management technology can itself predict the optimal timing of } \\
\text { individual stages based on accumulated information about their labor intensity, } \\
\text { choice of equipment loading route and competencies of intelligent agents. }\end{array}$} \\
\hline 15. Relevant SDGs & \multicolumn{2}{|c|}{ Industry, Innovation, and Infrastructure } \\
\hline
\end{tabular}




\subsection{Professional Images of Intelligent Agents}

Professional images of creative acts of intellectual agents indicate belonging to a certain profession. Professional images are a cognitive component of intelligent agents. The substantive components of professional images are creative functions, process and professional result of creative acts, criteria for assessing the achievements of the result. Professional images include an owl of evaluation characteristics and associated behavioral actions. The component composition of the professional image is described by the attributes of live information of the real environment based on an ethical standard (Bryndin, 2020a).

\section{Intelligent Agent Creative Ensemble Platform}

Intellectual agents may have psychological, analytical, research, language, professional and behavioral hybrid competencies.

The research competence of intellectual agent ensembles requires to master and receive new creative acts to model the implementation of the proposed idea, work with various sources of creative processes of the virtual environment, explore such topics, conduct experimental observations, propose solutions to the proposed idea. The research competence allow to independently and in cooperation with a specialist to implement plans for the resolution of which there is no complete set of accumulated funds.

Analytical competencies, through the analysis of live information, extend the requirements for specific creative processes to target processes. Laying out the plan on components (A, B, C). Consider the data and identify the main creative acts. Determines the reason and consequence "if A..., then B." and use this to compose creative processes. They analyze complex situations, considering several possible causes and consequences. They conduct a comprehensive analysis of complex data, and by analyzing complex situations, they find a solution to the plan.

The process of self-organization of ensembles of intellectual agents is carried out according to the law of structural harmony of the system: generalized gold sections are invariants, on the basis and through which in the process of self-organization of the system they gain a harmonious structure, stationary mode of existence, structural-functional stability.

In recent years, cognitive systems with functional self-organization technologies have appeared (Banerjee, 2020; Papadopoulos, Antona, \& Stephanidis, 2021; Chacón, Ponsa, \& Angulo, 2020; Wang, 2020; 2021; Zhang, Zeng, Pan, Shi, \& Lu, 2021; Sugali, Sprunger, \& Venkata, 2021; Babulak, 2021; Bryndin, 2021c). A fundamental step in describing such systems was taken by a Danish scientist who worked in America for many years, Per Buck in the theory of self-organized criticality (Buck, 2013). The title emphasizes that the system self-organizes into a critical state in which its dynamics acquire large-scale invariance in collective interaction in the network that develops as a result of self-organization. This approach is called "connectionism" (from English to connect connect).

The steady distribution of positive and negative responses of interacting links according to the law of the golden section determines the critical value of the intellectual agents of the ensemble. An ensemble having the number of necessary intellectual agents of equal or more critical importance is capable of self-realization and obtaining the necessary result. Determining the critical values of the ensembles of intelligent agents for the implementation of various sets of functions and competencies will help create a universal large ensemble to implement creative processes and designs according to the law of the golden section. To implement and maintain this project requires ultra-powerful supercomputers (Bryndin, 2019b ).

\section{Modeling of Creative Activities by Intelligent Agent Ensembles in Virtual Environment}

Modeling of creative activity by ensembles of intellectual agents in a virtual environment is carried out by ethical communications of images of creative acts of intellectual agents. Intellectual agents model professional, ethical, synergistic, causal, functional, associative-communicative and technological competencies of creative acts.

Modeling helps build creative practice in real time and at the same time use it to train intelligent agents. Modeling determines the ethical status of intelligent agents and the limits of professional image attribute values. The ethical state of intellectual agents within the values of the attributes of professional images contribute to their ethical communications.

Ethical communications are based on a system of stable forms of communication, prescribed by society as rules of behavior to establish contact of interlocutors, maintain communication in a chosen tone, respectively, their social roles and role positions relative to each other, and mutual relations in a professional environment. The degree of ownership of creative ethical etiquette determines the degree of professional fitness. Knowledge of creative ethical etiquette is the key to success in the implementation of creative design. 
Specialists in various fields have a need to summarize the experience of creative communication in one form or another and correlate it with the standards of ethics developed by humanity. In the field of creative relations, an objective assessment is introduced from an ethical point of view. Thus, taking into account the factors that form and determine creative etiquette, compliance with etiquette standards, contributes to the efficiency and efficiency of achieving the result with professional images of intellectual agents.

Communicative ethical behavior is a component of culture. Its core is values and principles, which are implemented in some norms and rules. Norms and rules are specific behavioral recommendations, prescriptions for behavior. These norms and rules are especially important to follow the professional images of intellectual agents in the creative field.

The ethics of creative communications is a set of moral norms, rules and ideas governing behavior and relations in the process of their production activities. The ethics of creative communications should be taken into account in its various manifestations: in the relationship between the ensembles of intellectual agents and the social environment, between the ensembles of intellectual agents in a virtual environment.

Taking into account the factors that form and determine linguistic, behavioral and active ethical communications of professional images, compliance with the norms and rules of communication and creative activity by intellectual agents contributes to the efficiency and effectiveness of their achievement of the result.

Ethical communication of professional images among themselves is carried out through intellectual agents with hybrid competencies, using mechanisms of coordination, cooperation or coalition according to ethical standard (Gershenson, 2020).

Diversification and mobility will align the life cycle of intelligent agents as a common benchmark for linking them to the environment. The environment is perceived through images and scenes. Scenes consist of a number of images. Scenes are static (paintings) and dynamic. Dynamic scenes are characterized by communications of creative acts of professional processes. Professional processes are composed of creative acts of intelligent agents. Some intellectual agents distinguish, others compare and find associations based on live information of cases of smart ethical communication-associative communications of ensembles of intellectual agents. Ensembles build trees from existing creative acts, both from top to bottom and from bottom to top. Based on the trees of creative acts, they apply branched models of logic to a set of live information data, taking into account the laws and features established during preliminary analysis, until they form a creative process through the tree of creative acts.

The recognition by experts of the execution of the plans of specialists by functional processes of ensembles of intellectual agents allows them to gain the status of creative processes.

\section{Conclusion}

The analytical and research capabilities of intelligent agent ensembles and their ability to process big data can help solve the pressing problems of mankind with powerful supercomputers. Robotic large ensembles of intelligent agents with smart hybrid competencies will gradually acquire human creative abilities. People will provide creative activities with them through wireless and mobile networks.

\section{References}

Babulak, E. (2021). Third Millennium Life Saving Smart Cyberspace Driven by AI and Robotics. COJ Robotics \& Artificial Intelligence, 1, 1-2. https://doi.org/10.4018/978-1-7998-3499-1.ch001

Banerjee, S. (2020). A framework for designing compassionate and ethical artificial intelligence and artificial consciousness. Interdisciplinary Description of Complex Systems: INDECS, 18(2-A), 85-95. https://doi.org/10.7287/peerj.preprints.3502v1

Bryndin, E. (2019a). Collaboration of intelligent interoperable agents via smart interface. International Journal on Data Science and Technology, 5(4), 66-72. https://doi.org/10.11648/j.ijdst.20190504.11

Bryndin, E. (2019b). Supercomputer BEG with Artificial Intelligence of Optimal Resource Use and Management by Continuous Processing of Large Programs. International Journal of Research in Engineering, 1(2), 9-14.

Bryndin, E. (2020a). Creative communication safe ethical artificial intelligence in the era of technological development. Software Engineering, 8(3), 13-23. https://doi.org/10.11648/j.se.20200803.11

Bryndin, E. (2021a). Information Essence of Spiritual Substance and Universe and Man in Cosmology. Saudi Journal of Humanities and Social Sciences, 6(12), (In print).

Bryndin, E. (2021b). Functional and Harmonious Self-Organization of Large Intellectual Agent Ensembles with Smart Hybrid Competencies. COJ Robotics \& Artificial Intelligence, 1(4), 1-11. 
https://doi.org/10.11648/j.ajsea.20211001.11

Bryndin, E. (2021c). Implementation of Competencies by Smart Ethical Artificial Intelligence in Different Environments. Software Engineering, 8, 24-33. https://doi.org/10.11648/j.se.20200804.11

Buck, P. (2013). How nature works: The theory of self-organized criticality. M.: Librocom, 2013.-276 pages.

Chacón, A., Ponsa, P., \& Angulo, C. (2020). On cognitive assistant robots for reducing variability in industrial human-robot activities. Applied Sciences, 10(15), 5137. https://doi.org/10.3390/app10155137

Gershenson, C. (2020). Guiding the self-organization of cyber-physical systems. Frontiers in Robotics and AI, 7, 41. https://doi.org/10.3389/frobt.2020.00041

Papadopoulos, G. T., Antona, M., \& Stephanidis, C. (2021). Towards open and expandable cognitive AI architectures for large-scale multi-agent human-robot collaborative learning. IEEE Access, 9, 73890-73909. https://doi.org/10.1109/ACCESS.2021.3080517

Sugali, K., Sprunger, C., \& Venkata, N. I. (2021). SOFTWARE TESTING: ISSUES AND CHALLENGES OF A RTIFICIAL INTELLIGENCE \& MACHINE L EARNING. International Journal of Artificial Intelligence and Applications (IJAIA), 12(1). https://doi.org/10.5121/ijaia.2021.12107

Wang, Y. (2020, November). How will autonomous systems and cognitive robots augment human intelligence. In The 2020 Future Technologies Conference (FTC'20), Vancouver, Canada.

Wang, Y. (2021, September). Emerging technologies for autonomous behavior generation at run-time by cognitive robots. In Int'l Conf. on Robot Intelligence Technologies and Applications (RITA'21), Porto, Portugal.

Zhang, T., Zeng, Y., Pan, R., Shi, M., \& Lu, E. (2021). Brain-Inspired Active Learning Architecture for Procedural Knowledge Understanding Based on Human-Robot Interaction. Cognitive Computation, 13(2), 381-393. https://doi.org/10.1007/s12559-020-09753-1

\section{Copyrights}

Copyright for this article is retained by the author(s), with first publication rights granted to the journal.

This is an open-access article distributed under the terms and conditions of the Creative Commons Attribution license (http://creativecommons.org/licenses/by/4.0/). 